\title{
Analgesic efficacy of remifentanil patient-controlled analgesia versus combined spinal-epidural technique in multiparous women during labour
}

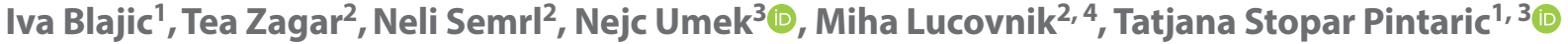 \\ ${ }^{1}$ Department of Anaesthesiology and Intensive Therapy, University Medical Centre Ljubljana, Slovenia \\ ${ }^{2}$ Faculty of Medicine, University of Ljubljana, Slovenia \\ 3 Institute of Anatomy, Faculty of Medicine, University of Ljubljana, Slovenia \\ ${ }^{4}$ Department of Perinatology, Division of Obstetrics and Gynaecology, University Medical Centre Ljubljana, Slovenia
}

\begin{abstract}
Objectives: To compare the analgesic profile of remifentanil patient-controlled analgesia (RPCA) and combined spinal-epidural analgesia technique (CSEA) in multiparous women during the entire labour. We hypothesized that CSEA would provide a better and more sustained pain reduction than RPCA.

Material and methods: A prospective observational trial under ID NCT02963337 at a university hospital in Slovenia 2017-2018. Analgesic efficacy, satisfaction with pain-relief, adverse effects, labour progress, and outcomes between RPCA (80) and CSEA (81) were compared.

Results: CSEA provided significantly lower pain scores during the entire labour. Compared to baseline, significant pain reduction was recorded in both groups after $15 \mathrm{~min}$. No difference was recorded compared to baseline with RPCA and CSEA after 45 and 90 mins, respectively. CSEA provided higher satisfaction than RPCA (5 [5-5] vs 5 [4-5], $p<0.0001$ ). More patients with CSEA opted for the same technique for the next labour [CSEA; 77 (95\%) vs RPCA; 65 (81\%), $p=0.003$ ]. No crossovers were observed. RPCA was associated with desaturation (34\%), bradypnea (21\%) and apnoea (25\%), which were transitional and easily managed. None had severe sedation. No differences were recorded in labour progress and outcomes. Apgar scores were reassuring in all neonates $(>8)$. None had umbilical artery $\mathrm{pH}<7.0$.

Conclusions: In multiparas, CSEA provided superior analgesia and satisfaction than RPCA. Nevertheless, RPCA provided a satisfactory experience, suggesting it could be used when neuraxial analgesia is not available, preferred, or contraindicated. In that case, constant presence of midwife is mandatory for management of clinically significant hypoventilation. Key words: labour analgesia; multiparity; combined spinal-epidural analgesia; remifentanil patient-controlled analgesia; pregnancy
\end{abstract}

Ginekologia Polska 2021; 92, 11: 797-803

\section{INTRODUCTION}

In multiparous women, many clinicians choose the combined spinal-epidural analgesia technique (CSEA) for labour analgesia due to its fast onset and a higher pain intensity reduction in the first 30 minutes compared to epidural analgesia [1]. When not immediately available, contraindicated or not preferred by the women or obstetricians, alternatives are required.

Remifentanil patient-controlled analgesia (RPCA) has a suitable profile for labour analgesia. Fast set-up, onset and a short duration of action make it particularly attractive for women with a faster labour progression [2]. A previous trial observed a higher satisfaction rate with pain relief in the RPCA subgroup of multiparous women compared with the epidural group [3]. Since the pain intensity was assessed as a secondary outcome and the CSEA technique proved advantageous compared to epidural analgesia, further studies comparing CSEA and RPCA are needed to allow multiparous women to make informed choices concerning pain-relieving potencies of available analgesic techniques.

\section{Corresponding author:}

Nejc Umek

Institute of Anatomy, Faculty of Medicine, University of Ljubljana, 2 Korytkova St, 1000 Ljubljana, Slovenia

Phone: 003861543 7314, e-mail: nejc.umek@mf.uni-lj.si 


\section{Objectives}

To our knowledge, the strategies of RPCA and CSEA have never been directly compared in a group of multiparous women. Thus, the primary aim of our study was to compare the pain intensity profiles of CSEA and RPCA during the whole labour using an 11-point numerical rating scale. The secondary outcomes were overall satisfaction with pain-relief, the incidence of adverse effects, labour progress, and labour outcomes.

\section{MATERIAL AND METHODS}

This prospective observational study was approved by the Republic of Slovenia National Medical Ethics Committee (Permit No. 91/04/16) and registered at the central database of ClinicalTrials.gov under the trial ID NCT02963337, (https://clinicaltrials.gov/ct2/show/NCT02963337?term $=0$ 2963337\&rank=1) on November 15, 2016. The study was conducted from January 2017 to September 2018 in the labour and delivery unit of the Perinatology Department, Division of Obstetrics and Gynaecology, University Medical Centre Ljubljana, with 6000 deliveries per year, neuraxial and remifentanil analgesia rate of $60 \%$ (ratio 1:1) and caesarean section rate of $21 \%$.

Consecutively admitted at the labour and delivery suit, multiparous women with singleton pregnancies in their active phase of first stage labour requesting pain relief were asked to participate in the study. They were informed about the two different analgesic options being studied, i.e., RPCA and CSEA, their advantages and disadvantages. After signing an informed consent form, they were allocated either to a RPCA or CSEA group based on their informed choices of labour analgesia. The inclusion criteria were age 18 to 55 , American Society of Anaesthesiologists (ASA) physical status 2 or 3, uncomplicated pregnancy at 37 0/7-40 6/7 weeks of gestation, absence of known foetal congenital abnormalities, vertex presentation, ongoing uterine contraction, cervical dilation 3 to $6 \mathrm{~cm}$ and normal cardiotocography (CTG). Exclusion criteria were preeclampsia, contraindications to CSEA (coagulation and neurological abnormalities, infection/fever) and remifentanil (opioid drug abuse, pethidine given within the two previous hours, known allergic reaction to remifentanil, morbid obesity with body mass index (BMI) $>40$ and obstructive sleep apnoea).

In the RPCA group, the women were introduced to the PCA pump (Rythmic ${ }^{\text {TM }}$ Evolution, Micrel Medical Devices, Athens, Greece) and told to use PCA at the start of each uterine contraction [4]. Remifentanil hydrochloride (Ultiva, GlaxoSmithKline, Oslo, Norway) was diluted in saline to a concentration of $40 \mathrm{\mu g} \mathrm{mL}^{-1}$ and administered stepwise from 20 to a maximum of $40 \mu \mathrm{g}$ with a bolus duration of 20 seconds and 2 minutes lockout interval with no background infusion. Dose adjustment was performed by the anaesthesiology staff at patient's request. The bolus dose was increased if pain intensity as assessed by an 11-point numerical rating scale (NRS; 0 is no pain and 10 the worst imaginable pain) increased and a patient's respiratory rate was $>9$ breaths $\mathrm{min}^{-1}$, oxygen saturation $\left(\mathrm{SpO}_{2}\right) \geq 94 \%$, heart rate $>50 \mathrm{~min}^{-1}$ and sedation score $\leq 2$ on a five-point categorical scale (scale 1-5: 1 = alert, 2 = slightly drowsy, 3 = drowsy, $4=$ very drowsy, $5=$ unarousable) [5-7]. The use of PCA was allowed until 5-10 minutes prior to cord clamping. Women in the RPCA group had one-to-one midwifery care. In accordance with the institutional standard operating protocol, women were continuously monitored with Capnostream ${ }^{\oplus}$ capnograph (Oridion $^{\oplus}$, Jeruzalem, Israel) with an oral-nasal cannula, sampling from both the nose and mouth (Oridion $\left.{ }^{\oplus}\right)$. Supplemental oxygen $\left(2 / \mathrm{min}^{-1}\right)$ was given to all patients via a nasal catheter. The respiratory monitor recorded continuous waveform of end tidal $\mathrm{CO}_{2}$ respiratory rate, $\mathrm{SpO}_{2}$ and heart rate with the alarms being activated by oxygen desaturation $\left(\mathrm{SpO}_{2}<94 \%\right)$, bradypnea (respiratory rate $<8 \mathrm{~min}^{-1}$ ) and apnoea longer than $20 \mathrm{sec}-$ onds, triggering staged interventions started with a verbal command to take a deep breath or a light tap in case of no response [8]. The anaesthesia provider recorded the triggered alarms from the monitor hourly. Foetal heart rate was continuously monitored with CTG (Hewlett Packard Viridia Series 50IP', Hewlett Packard, Palo Alto, CA, USA or Philips $50 \mathrm{XM}^{\circ}$, Amsterdam, Netherlands). Remifentanil was stopped if pathological CTG changes occurred including decreased variability, bradycardia, tachycardia, or late decelerations.

In the CSEA group, all blocks were performed in the sitting position. The epidural space was located with an 18-gauge Tuohy needle (PORTEX ${ }^{\circ}$ CSE cure ${ }^{\circ}$ Combined Spinal Epidural System, Smiths Medical, Minnesota, USA) inserted in the midline using loss of resistance to air or saline at the L3-L4 or L4-L5 interspace, followed by needle-through-needle insertion of 27-gauge spinal needle. After obtaining a cerebrospinal fluid, $2.5 \mathrm{mg}$ bupivacaine hydrochloride with $25 \mu \mathrm{g}$ of fentanyl (total volume of $1 \mathrm{~mL}$ ) was injected, followed by a 20-gauge multi-hole catheter insertion into the epidural space [1]. Epidural anaesthesia was managed using patient-controlled boluses of $6 \mathrm{~mL}$ of $0.1 \%$ bupivacaine with $2 \mu \mathrm{g} \mathrm{mL}^{-1}$ fentanyl every 15 minutes with no background infusion via the PCA pump (Rhythmic $^{T M}$ Evolution, Micrel Medical Devices, Athens, Greece). In accordance with local protocol, $5 \mathrm{mg}$ of ephedrine was injected intravenously into all women immediately after the intrathecal analgesic injection to prevent hypotension.

Demographic and medical data were obtained by means of personal interviews before initiation of analgesia and during the labour. Pain intensity was assessed using an 11-point NRS, where 0 is no pain and 10 the worst imaginable pain. NRS scores, sedation level, automatic readings 
of non-invasive systolic and diastolic blood pressure, heart rate and $\mathrm{SpO}_{2}$ were recorded immediately before starting the PCA (baseline), every 15 minutes during the first hour and every 30 minutes thereafter. Immediately after delivery, satisfaction with pain relief was evaluated using a five-point categorical scale ( $5=$ very good, $4=$ good, 3 = moderate, 2 = poor, 1 = very poor). At the same time, each parturient was also asked if she would choose the same analgesic technique for her next delivery or recommend it to others.

Data on labour progress (first and second stage labour duration, mean cervical dilation rate) and labour outcome were recorded for each patient, including the use of oxytocin, cumulative dose of oxytocin administered, and mode of delivery (spontaneous vaginal, instrumental vaginal, caesarean section). Cervical dilation was assessed by the midwife, and all changes were recorded until the delivery was completed. The mean cervical dilation rate was defined as 10 minus the cervical dilatation observed at the last examination before the start of analgesia divided by the duration of labour [9].

The total dose of remifentanil was registered automatically in the PCA pump and recorded for each patient. Data concerning nausea, vomiting and itching were also collected. Oral temperature was measured both at the onset of analgesia and within 1 hour of delivery. After delivery, Apgar scores at 1 and 5 minutes were recorded, and umbilical blood gas analysis performed according to the standard procedures. Neonatal need for naloxone and resuscitation were also noted.

\section{Statistical analysis}

The sample size was calculated based on the primary outcome of pain relief during CSEA in multiparous women measured on an 11-point scale ranging from 0 to 10 . If the true difference between the two studied groups is 1 (on 11-point scale with estimated standard deviation of 2.2), we needed to study 77 subjects in each group to be able to reject the null hypothesis that the population means of the two groups are not equal with probability (power) of 0.8 . The Type I error probability associated with the test of this null hypothesis is 0.05 [10]. The Shapiro-Wilk test was used to evaluate the data for normality. If the normality and equal variance assumptions were met, it was followed by Student's t test; otherwise, the Mann Whitney U test was used. Proportions were compared using Fisher's exact test. NRS scores at different time points during labour were compared using mixed-effect analysis followed by Sidak post-hoc tests that corrected the $p$ values for the subgroup analyses and Friedman test. Statistical analysis was performed with the GraphPad Prism 8 (GraphPad Software, San Diego CA, USA). The difference was considered statistically significant at $p<0.05$. The data are presented as frequency (proportion \%), mean \pm standard deviation (SD) and median [inter-quartile range $(I Q R)]$.

\section{RESULTS}

One hundred and sixty-two multiparous women were enrolled in the study. One hundred and sixty-one delivered vaginally. Caesarean section was performed on one parturient due to dystocia (Fig. 1). Demographic data and obstetric end points are presented in Table 1. No differences were recorded between the groups except for one cumulative dose of oxytocin which was higher in the CSEA group.

CSEA provided significantly lower pain scores compared to RPCA up to 150 min of labour duration (Tab. 2). After $15 \mathrm{~min}$, a significant pain reduction was recorded in both groups. After $45 \mathrm{~min}$, the pain reduction was no longer statistically significant from the baseline in the RPCA group. In the CSEA group, by contrast, the pain reduction remained statistically significant from the baseline up to $90 \mathrm{~min}$ (Fig. 2).

CSEA provided higher satisfaction rate with labour analgesia compared to RPCA (5 [5-5] vs 5 [4-5], p < 0.0001). More patients from the CSEA group opted for the same technique for their next labour [CSEA; 77 (95\%) vs RPCA; $65(81 \%), p=0.003]$. No difference between techniques was recorded in recommending the respective technique to others [CSEA; 77 (95\%) vs RPCA; 72 (90\%), $p=0.12$ ]. No crossovers were observed.

Drug consumption and side effects are presented in Table 3. No differences were observed in the incidence of nausea and vomiting, or body temperature between the groups. Pruritus was more frequent with CSEA. Maternal hypotension and bradycardia were rare with no differences recorded between the groups. Two women with RPCA were drowsy, the rest were either alert or slightly drowsy. In the CSEA group, by contrast, all women except one were alert. RPCA was associated with periods of desaturation, bradypnea and apnoea which were transitional and easily managed. No serious respiratory depression or other serious complication occurred. Apgar scores were reassuring in all neonates $(>8)$, both at 1 and 5 minutes after birth. None of them exhibited umbilical artery $\mathrm{pH}<7.0$ (Tab. 1).

\section{DISCUSSION}

This study has shown a superiority of CSEA over RPCA for labour analgesia in multiparous women. Our results reaffirm that no policy of opioid analgesia during labour is as effective as epidural pain relief [11]. Nevertheless, both CSEA and RPCA provided fast onset of analgesia with the efficacy ratio of $100 \%$ versus $25 \%$ in favour of CSEA which lasted up to $30 \mathrm{~min}$. Thereafter, CSEA provided consistent pain reduction, whereas with RPCA the pain scores increased reaching the pre-treatment level within an hour. This, how- 


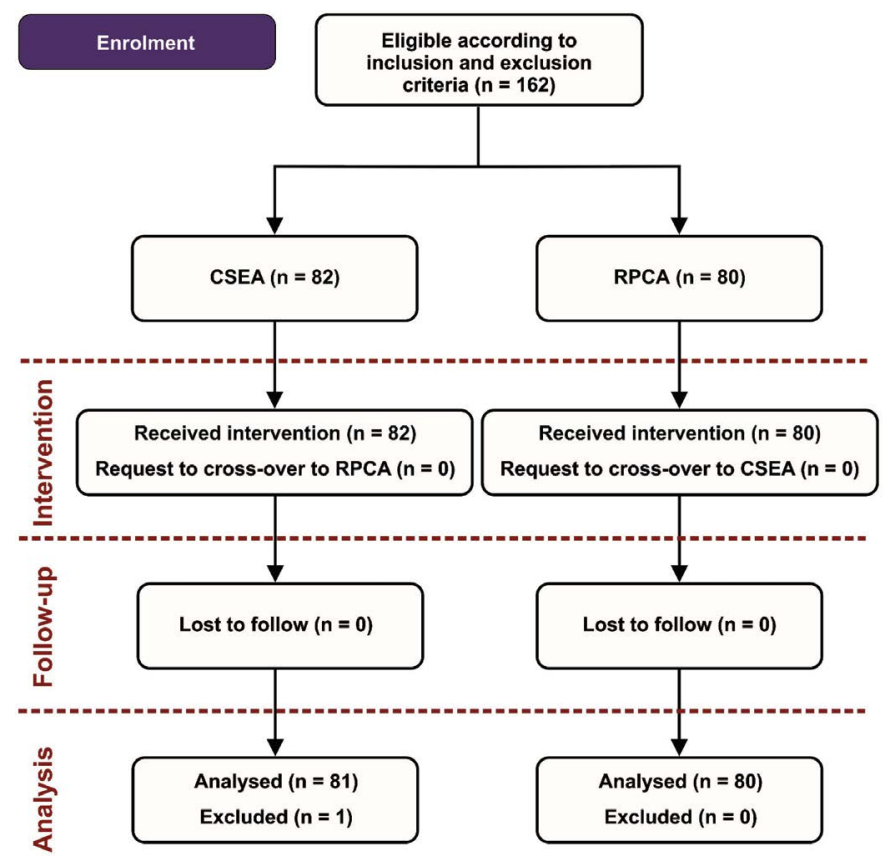

Figure 1. Study design

\begin{tabular}{|c|c|c|c|}
\hline & CSEA $n=81$ & RPCA $n=80$ & p-value \\
\hline ASA physical status $(2 / 3)$ & $76 / 5$ & $74 / 6$ & 0.766 \\
\hline Maternal age [y] & $33 \pm 5$ & $32 \pm 5$ & 0.760 \\
\hline Weight [kg] & $81 \pm 13$ & $84 \pm 14$ & 0.147 \\
\hline BMI $\left[\mathrm{kg} \mathrm{m}^{-2}\right]$ & $29.1 \pm 4.7$ & $29.8 \pm 5.4$ & 0.519 \\
\hline Gestational age [weeks] & $39 \pm 1$ & $39 \pm 2$ & 0.364 \\
\hline Parity & $2[2-2]$ & $2[2-2]$ & 0.913 \\
\hline Cervix dilatation at initiation of analgesia $[\mathrm{cm}]$ & $4.0 \pm 0.8$ & $4.4 \pm 0.6$ & 0.004 \\
\hline Duration of $1^{\text {st }}$ stage of labour [min] & $90 \pm 59$ & $78 \pm 47$ & 0.156 \\
\hline Duration of $2^{\text {nd }}$ stage of labour [min] & $22 \pm 16$ & $19 \pm 15$ & 0.222 \\
\hline Speed of cervical dilation $>1.5 \mathrm{~cm} \mathrm{~h}^{-1}$ & $63(78 \%)$ & $69(86 \%)$ & 0.218 \\
\hline Labour induction & $34(42 \%)$ & $28(35 \%)$ & 0.419 \\
\hline Augmentation with oxytocin & $74(91 \%)$ & $71(89 \%)$ & 0.609 \\
\hline Cumulative oxytocin dose (IU) & $14 \pm 8$ & $11 \pm 6$ & 0.017 \\
\hline Instrumental delivery & $0(0 \%)$ & $0(0 \%)$ & 0.999 \\
\hline Episiotomy & $74(91 \%)$ & 71 (89\%) & 0.713 \\
\hline Postpartum haemorrhage $\geq 500 \mathrm{~mL}$ & $4(5 \%)$ & $3(4 \%)$ & 0.999 \\
\hline Perineal tear $\geq 3^{\text {rd }}$ degree & $1(1 \%)$ & $0(0 \%)$ & 0.999 \\
\hline Vertex OA position & 77 (94\%) & 75 (94\%) & 0.720 \\
\hline Vertex OP position & $3(4 \%)$ & $5(6 \%)$ & 0.720 \\
\hline Birth weight $[\mathrm{g}]$ & $3509 \pm 471$ & $3469 \pm 430$ & 0.581 \\
\hline Head circumference $[\mathrm{cm}]$ & $35.2 \pm 1.3$ & $34.9 \pm 1.2$ & 0.130 \\
\hline Apgar 1 min & $9[9-9]$ & $9[9-9]$ & 0.999 \\
\hline Apgar 5 min & 9 [9-9] & 9 [9-9] & 0.999 \\
\hline Umbilical artery $\mathrm{pH}$ & $7.25 \pm 0.09$ & $7.28 \pm 0.08$ & 0.058 \\
\hline Umbilical vein $\mathrm{pH}$ & $7.32 \pm 0.07$ & $7.34 \pm 0.07$ & 0.233 \\
\hline Foetal bradycardia & $2(2 \%)$ & $4(5 \%)$ & 0.277 \\
\hline
\end{tabular}

Values are number (proportion \%), mean \pm SD or median [IQR]; ASA - American Society of Anaesthesiologist's physical status; CSEA — combined spinal and epidural analgesia; RPCA - remifentanil patient-controlled analgesia 
Table 2. Numerical rate scale (NRS) scores in multiparous women

\begin{tabular}{|l|l|l|l|l|}
\hline & CSEA & RPCA & Effect size & \#P-value \\
\hline NRS at inclusion & $8.0 \pm 1.7, n=81$ & $7.9 \pm 1.4, n=80$ & 0.1 & 0.999 \\
\hline NRS at $15 \mathrm{~min}$ & $1.7 \pm 2.5, n=80^{* *}$ & $6.1 \pm 1.7, n=78^{* *}$ & 4.4 & $<0.0001$ \\
\hline NRS at $30 \mathrm{~min}$ & $1.3 \pm 2.2, n=77^{* *}$ & $6.3 \pm 1.9, n=71^{* *}$ & 5.0 & $<0.0001$ \\
\hline NRS at $45 \mathrm{~min}$ & $1.8 \pm 2.3, n=70^{* *}$ & $6.4 \pm 2.0, n=65^{* *}$ & 4.6 & $<0.0001$ \\
\hline NRS at $60 \mathrm{~min}$ & $2.0 \pm 2.1, n=58^{* *}$ & $7.0(1.9), n=57^{*}$ & 5.0 & $<0.0001$ \\
\hline NRS at $90 \mathrm{~min}$ & $3.2 \pm 2.4, n=47^{* *}$ & $7.6 \pm 1.9, n=40$ & 4.4 & $<0.0001$ \\
\hline NRS at $120 \mathrm{~min}$ & $5.0 \pm 2.2, n=32^{* *}$ & $8.0 \pm 1.9, n=22$ & 3.0 & $<0.0001$ \\
\hline NRS at $150 \mathrm{~min}$ & $5.8 \pm 2.7, n=19^{*}$ & $8.7 \pm 1.3, n=9$ & 2.9 & 0.008 \\
\hline NRS at $180 \mathrm{~min}$ & $5.4 \pm 2.5, n=10^{*}$ & $7.5 \pm 1.0, n=4$ & 2.1 & 0.370 \\
\hline
\end{tabular}

Values are expressed as means \pm SD. RPCA — remifentanil patient-controlled analgesia; CSEA - combined spinal-epidural analgesia. Effect size, absolute difference between means. \#p values for RPCA vs CSEA at the same time point; ${ }^{*} p=0.01-0.05$, ${ }^{* *} p<0.0001 v s$ NRS score at inclusion of the same study group (mixed-effects analysis with Sidak correction)

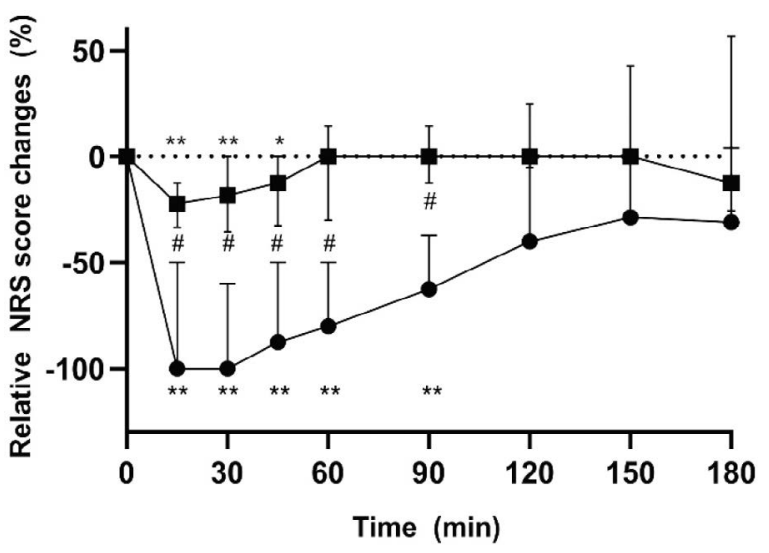

Figure 2. Relative numerical rating scale (NRS) score changes from the baseline value in multiparous women. Remifentanil patientcontrolled analgesia (RPCA) $(\bigotimes)$ or combined spinal-epidural analgesia (CSEA) $(\bigotimes)$ during labour. Data are medians and inter-quartile ranges. ${ }^{*} \mathrm{p}<0.01,{ }^{* *} \mathrm{p}<0.0001$ vs baseline NRS score of the same study group; \#p $<0.0001$ relative NRS score changes of the RPCA vs CSEA study group at the same time point (Friedman test)

ever, does not imply a lack of remifentanil analgesic efficacy as pain scores are known to increase during labour [12]. This is particularly true for multiparas where a dramatic increase in pain intensity is observed at the end of first-stage labour and during the second-stage due to rapid and abrupt foetal descent [13]. To improve the pain management in this group of women, RPCA should be initiated later in the first-stage labour with a faster dose increase over time [12, 14]. Similar analgesic efficacy of remifentanil has been reported by others using dose range like ours $[2,4,15]$. When higher bolus doses were used much lower pain scores were achieved on the account of severe sedation and desaturation which points to a narrow analgesic window of remifentanil [6].

We observed a higher satisfaction rate with CSEA than RPCA which could be attributed to complete pain relief followed by more efficacious labour analgesia. Nevertheless,

\begin{tabular}{|c|c|c|c|}
\hline & $\begin{array}{l}\text { CSEA } \\
\mathrm{n}=81\end{array}$ & $\begin{array}{l}\text { RPCA } \\
\mathrm{n}=80\end{array}$ & $P$-value \\
\hline $\begin{array}{l}\text { Remifentanil cumulative } \\
\text { dose [mg] }\end{array}$ & NA & $\begin{array}{l}0.600[0.343- \\
1.018]\end{array}$ & \\
\hline $\begin{array}{l}\text { Number of boluses } \\
\text { needed }\end{array}$ & $2[1-3]$ & 22 [14-34] & NA \\
\hline Pruritus & $18(22 \%)$ & $1(1 \%)$ & $<0.0001$ \\
\hline Nausea or vomiting & $4(5 \%)$ & $4(5 \%)$ & 0.999 \\
\hline $\begin{array}{l}\text { Temperature at initiating } \\
\text { analgesia }\left[{ }^{\circ} \mathrm{C}\right]\end{array}$ & $36.7 \pm 0.3$ & $36.6 \pm 0.3$ & 0.292 \\
\hline $\begin{array}{l}\text { Temperature within } 1 \text { hour } \\
\text { after delivery }\left[{ }^{\circ} \mathrm{C}\right]\end{array}$ & $37.0 \pm 0.4$ & $36.9 \pm 0.5$ & 0.297 \\
\hline $\begin{array}{l}\text { Systolic blood pressure } \\
\text { drop }>20 \mathrm{mmHg}\end{array}$ & $6(8 \%)$ & $4(5 \%)$ & 0.746 \\
\hline $\begin{array}{l}\text { Heart rate drop below } \\
60 \mathrm{~min}^{-1}\end{array}$ & $1(1 \%)$ & $0(0 \%)$ & 0.999 \\
\hline Desaturation $\left(\mathrm{SpO}_{2}<94 \%\right)$ & NA & $27(34 \%)$ & \\
\hline $\begin{array}{l}\text { Bradypnea (respiratory } \\
\text { rate }<8 \mathrm{~min}^{-1} \text { ) }\end{array}$ & NA & $17(21 \%)$ & \\
\hline $\begin{array}{l}\text { Apnoea (respiratory } \\
\text { pause }>20 \text { s) }\end{array}$ & NA & $20(25 \%)$ & \\
\hline \multicolumn{4}{|l|}{$\begin{array}{l}\text { The highest sedation score } \\
\text { during labour: }\end{array}$} \\
\hline 1 (alert) & $80(99 \%)$ & $66(82 \%)$ & 0.0003 \\
\hline 2 (slightly drowsy) & $1(1 \%)$ & $12(15 \%)$ & 0.0012 \\
\hline 3 (drowsy) & $0(0 \%)$ & $2(3 \%)$ & 0.245 \\
\hline $\begin{array}{l}\geq 4 \text { (very drowsy, } \\
\text { unarousable) }\end{array}$ & $0(0 \%)$ & $0(0 \%)$ & 0.999 \\
\hline
\end{tabular}

Values are expressed as an absolute number (proportion \%), mean \pm SD or median [IQR]; RPCA — remifentanil patient-controlled analgesia; CSEA — combined spinal-epidural analgesia; NA — not applicable

RPCA still provided a satisfactory experience, as demonstrated by the majority (83\%) of women grading their satisfaction with pain relief as good or very good, and the absence of crossovers indicating that other favourable factors were con- 
sidered more important than pain relief itself [3]. Wilson et al., in their randomized trial, reported a $19 \%$ conversion rate from RPCA to epidural analgesia [11]. This difference in incidence may be attributable to the free choice of remifentanil in our study [16]. Our findings are in agreement with those who considered RPCA an attractive option for analgesia with acceptable satisfaction scores, particularly for multiparas, who usually took the advantage of fast delivery combined with rapid availability and short use of pain relief [3].

Our results confirm the well-known risk of respiratory complications associated with RPCA [8]. While the rates of adverse effects appear high, these rates are similar to those reported in earlier studies $[4,14,16,17]$. Nevertheless, no clinically important hypoventilation or other severe complications were encountered in any of these cases. That could be attributed to obligatory use of supplemental oxygen in all our parturients. Previous studies have demonstrated maternal desaturation in $40-70 \%$ of women using RPCA, with supplemental oxygen reducing the overall number but not the severity of episodes $[14,18]$. Somewhat encouragingly, poorer Apgar scores or lower neonatal pH have not been found to correlate with episodes of maternal desaturation $[18,19]$. Moreover, all women with RPCA in our unit are monitored with constant presence of a midwife which enables a prompt response to clinically significant hypoventilation. This, however, may not be universally feasible due to increasing midwifery vacancies and a rise in the proportion of units in our country which report insufficient findings to meet even the current demands on service [20].

As with previous reports, no adverse neonatal outcomes were observed with CSEA or RPCA in our study $[2-4,7,8,15$, $17,21]$. Neither was there any difference observed in the first and second stage labour duration. That could be attributed to a higher cumulative dose of oxytocin used in the CSEA group [22]. A retrospective analysis comparing RPCA and epidural analgesia with respect to labour outcomes found a shorter active labour and a higher rate of spontaneous delivery in the RPCA group [23]. The reason, according to experimental studies, is that epidural analgesia blocks a spinal reflex release of oxytocin and subsequently prostaglandin $\mathrm{F}$, which results in prolonged labour. Furthermore, lumbar spinal blockade by transection of the vagal or pelvic nerves suppress cervical ripening and uterine contractions and delays birth [24, 25].

Our study has limitations. First, due to its observational nature it could not exclude potential biases and confounders. For instance, pain scores, satisfaction and side effects were recorded by a non-blinded observer, which may favour bias. Second, the satisfaction with labour experience, including the pain-relief satisfaction during labour, depends heavily on the progress of labour and maternal as well as neonatal outcomes. Therefore, we compared progress of labour, need for labour augmentation and perinatal outcomes in the two study groups. Since no significant differences were observed, the groups may be considered as comparable. Nevertheless, despite the limitations of the study's design, giving women a choice in selecting their mode of labour analgesia may have significantly contributed to their overall satisfaction.

\section{CONCLUSIONS}

Under condition of our study, CSEA provided superior analgesia and a higher satisfaction rate compared to RPCA in multiparous women. Nevertheless, RPCA appeared to provide a satisfactory experience, suggesting it could be used when neuraxial analgesia is not quickly available, if contraindicated or not preferred by women or obstetricians. In this case, monitoring with a constant presence of a competent midwife is mandatory for timely management of clinically significant hypoventilation.

\section{Acknowledgments}

This work was supported by the Slovenian Research Agency (Grant No: P3-0043) and tertiary funding from Clinical department of Anaesthesiology and Intensive Therapy, University Clinical Centre (Ljubljana, Slovenia) (Grant No: TP 20180063). We are tankful to Dr. Dragica Becanovic, Dr. Dragan Graovac and residents from the Department of Anaesthesiology and Intensive Therapy, University Medical Centre Ljubljana for help in recruiting the patients and to Chiedozie K. Ugwoke for manuscript proofreading.

\section{Conflict of interest}

The authors declare that they have no conflicts of interests.

\section{REFERENCES}

1. Goodman SR, Smiley RM, Negron MA, et al. A randomized trial of breakthrough pain during combined spinal-epidural versus epidural labor analgesia in parous women. Anesth Analg. 2009; 108(1): 246-251, doi: 10.1213/ane.0b013e31818f896f, indexed in Pubmed: 19095858.

2. Freeman LM, Bloemenkamp KW, Franssen MT, et al. Patient controlled analgesia with remifentanil versus epidural analgesia in labour: randomised multicentre equivalence trial. BMJ. 2015; 350: h846, doi: 10.1136/bmj. h846, indexed in Pubmed: 25713015.

3. Logtenberg S, Oude Rengerink K, Verhoeven CJ, et al. Labour pain with remifentanil patient-controlled analgesia versus epidural analgesia: a randomised equivalence trial. BJOG. 2017; 124(4): 652-660, doi: 10.1111/1471-0528.14181, indexed in Pubmed: 27348853.

4. Blair JM, Hill DA, Fee JP. Patient-controlled analgesia for labour using remifentanil: a feasibility study. Br J Anaesth. 2001; 87(3): 415-420, doi: 10.1093/bja/87.3.415, indexed in Pubmed: 11517125.

5. Weiniger CF, Carvalho B, Stocki D, et al. Analysis of Physiological Respiratory Variable Alarm Alerts Among Laboring Women Receiving Remifentanil. Anesth Analg. 2017; 124(4): 1211-1218, doi: 10.1213/ANE.0000000000001644, indexed in Pubmed: 27870644.

6. Tveit TO, Seiler S, Halvorsen A, et al. Labour analgesia: a randomised, controlled trial comparing intravenous remifentanil and epidural analgesia with ropivacaine and fentanyl. Eur J Anaesthesiol. 2012; 29(3): 129-136, doi: 10.1097/EJA.0b013e32834dfa98, indexed in Pubmed: 22249153. 
7. Tveit TO, Halvorsen A, Seiler S, et al. Efficacy and side effects of intravenous remifentanil patient-controlled analgesia used in a stepwise approach for labour: an observational study. International Journal of Obstetric Anesthesia. 2013; 22(1): 19-25, doi: 10.1016/j.ijoa.2012.09.003.

8. Stocki D, Matot I, Einav S, et al. A randomized controlled trial of the efficacy and respiratory effects of patient-controlled intravenous remifentanil analgesia and patient-controlled epidural analgesia in laboring women. Anesth Analg. 2014; 118(3): 589-597, doi: 10.1213/ANE.0b013e3182a7cd1b, indexed in Pubmed: 24149580.

9. Robson MS. Active management of labour. Continual audit is important. BMJ. 1994; 309(6960): 1015, doi: 10.1136/bmj.309.6960.1015a, indexed in Pubmed: 7950697.

10. Todd KH, Funk KG, Funk JP, et al. Clinical significance of reported changes in pain severity. Ann Emerg Med. 1996; 27(4): 485-489, doi: 10.1016/s0196-0644(96)70238-x, indexed in Pubmed: 8604867.

11. Wilson MJA, MacArthur C, Hewitt CA, et al. RESPITE Trial Collaborative Group. Intravenous remifentanil patient-controlled analgesia versus intramuscular pethidine for pain relief in labour (RESPITE): an open-label, multicentre, randomised controlled trial. Lancet. 2018; 392(10148): 662-672, doi: 10.1016/S0140-6736(18)31613-1, indexed in Pubmed: 30115484.

12. Douma MR, Verwey RA, Kam-Endtz CE, et al. Obstetric analgesia: a comparison of patient-controlled meperidine, remifentanil, and fentanyl in labour. Br J Anaesth. 2010; 104(2): 209-215, doi: 10.1093/bja/aep359, indexed in Pubmed: 20008859.

13. Lowe N. Parity Pain During Parturition. Journal of Obstetric, Gynecologic \&Neonatal Nursing. 1987; 16(5):340-346, doi: 10.1111/j.1552-6909.1987. tb01593.x.

14. Douma MR, Middeldorp JM, Verwey RA, et al. A randomised comparison of intravenous remifentanil patient-controlled analgesia with epidural ropivacaine/sufentanil during labour. Int J Obstet Anesth. 2011; 20(2): 118-123, doi: 10.1016/j.ijoa.2010.11.009, indexed in Pubmed: 21376564.

15. Melber AA, Jelting $Y$, Huber $M$, et al. Remifentanil patient-controlled analgesia in labour: six-year audit of outcome data of the RemiPCA SAFE Network (2010-2015). Int J Obstet Anesth. 2019; 39: 12-21, doi: 10.1016/j.ijoa.2018.12.004, indexed in Pubmed: 30685299.

16. Murray $H$, Hodgkinson $P$, Hughes $D$. Remifentanil patient-controlled intravenous analgesia during labour: a retrospective observational study of 10 years' experience. Int J Obstet Anesth. 2019; 39: 29-34, doi: 10.1016/j.ijoa.2019.05.012, indexed in Pubmed: 31230993.

17. Volikas I, Butwick A, Wilkinson C, et al. Maternal and neonatal side-effects of remifentanil patient-controlled analgesia in labour. Br J Anaesth. 2005; 95(4): 504-509, doi: 10.1093/bja/aei219, indexed in Pubmed: 16113038.

18. Messmer AA, Potts JM, Orlikowski CE. A prospective observational study of maternal oxygenation during remifentanil patient-controlled analgesia use in labour. Anaesthesia. 2016; 71(2): 171-176, doi: 10.1111/anae.13329, indexed in Pubmed: 26617275.

19. Griffin RP, Reynolds F. Maternal hypoxaemia during labour and delivery: the influence of analgesia and effect on neonatal outcome. Anaesthesia. 1995; 50(2): 151-156, doi: 10.1111/j.1365-2044.1995.tb15101.x, indexed in Pubmed: 7710029.

20. Prelec A, Verdenik I, Poat AA. comparison of frequency of medical interventions and birth outcomes between the midwife led unit and the obstetric unit in low-risk primiparous women. Slov Nurs Rev. 2014; 48(3): 166-176.

21. Lin R, Tao Y, Yu Y, et al. Intravenous remifentanil versus epidural ropivacaine with sufentanil for labour analgesia: a retrospective study. PLoS One. 2014; 9(11): e112283, doi: 10.1371/journal.pone.0112283, indexed in Pubmed: 25386749.

22. Anim-Somuah M, Smyth R, Cyna A, et al. Epidural versus non-epidural or no analgesia for pain management in labour. Cochrane Database of Systematic Reviews. 2018, doi: 10.1002/14651858.cd000331.pub4.

23. Thorbiörnson A, da Silva Charvalho P, Gupta A, et al. Duration of labor, delivery mode and maternal and neonatal morbidity after remifentanil patient-controlled analgesia compared with epidural analgesia. Eur J Obstet Gynecol Reprod Biol X. 2020; 6: 100106, doi: 10.1016/j. eurox.2019.100106, indexed in Pubmed: 32300757.

24. Flint AP, Forsling ML, Mitchell MD. Blockade of the Ferguson reflex by lumbar epidural anaesthesia in the parturient sheep: effects on oxytocin secretion and uterine venous prostaglandin F levels. Horm Metab Res. 1978; 10(6):545-547, doi: 10.1055/s-0028-1093388, indexed in Pubmed: 744573.

25. Clyde LA, Lechuga TJ, Ebner CA, et al. Transection of the pelvic or vagus nerve forestalls ripening of the cervix and delays birth in rats. Biol Reprod. 2011; 84(3): 587-594, doi: 10.1095/biolreprod.110.086207, indexed in Pubmed: 21106964 